\title{
Arbor
}

\section{Botánica económica y etnobotánica en al-Andalus (Península Ibérica: siglos X-XV): un patrimonio desconocido de la humanidad}

\section{J.E. Hernández Bermejo, E. García Sánchez}

Arbor CLXVI, 654 (Junio 2000), 311-331 pp.

\section{Introducción}

El protagonismo que la Península Ibérica ha jugado en la introducción e intercambio de especies entre los Continentes Europeo y Americano es un hecho incuestionable que ha sido objeto de numerosos trabajos y que constituye un tema del que todavía podemos esperar muchas aportaciones futuras. Los años inmediatos al de 1992 significaron una nueva tentación para impulsar la investigación sobre el transporte y transferencia de especies y culturas entre los pueblos de América y Europa. La mayor parte de las aportaciones han estudiado las impresiones que los primeros exploradores, colonos, cronistas, médicos y naturalistas españoles recibieron al pisar las tierras americanas y las especies por ellos transportadas (Crosby (1991), Dawson (1960), Estrella (1986), Del Río Moreno (1991). En sentido inverso, podemos mencionar el buen nivel de conocimiento ya conseguido sobre el transporte de especies americanas hacia Europa a partir del siglo XVIII (García París, 1991) y en bastante menor grado lo sucedido durante los dos primeros siglos (XVI y XVII) periodo del que nos hemos ocupado en algunos de nuestros trabajos (Hernández Bermejo y Lora González (1994), Hernández Bermejo y León, eds. (1995), Lora González (1994).

Este trabajo es una versión modificada del publicado en 1998 en la revista Economic Botany 52(1): 15-26, bajo el título «The Economic Botany and Ethnobotany in al-Andalus (Iberian Peninsula: 10th-15th Centuries): an Unknown Heritage of Mankind». 
Comprender el papel e influencia de España en el transporte de especies desde el Viejo Mundo y la transferencia de su cultura, de sus costumbres y técnicas tradicionales, no podrá conseguirse sin conocer previamente los orígenes e historia de las especies y culturas ibéricas, europeas y mediterráneas que junto con otras influencias asiáticas y africanas, fueron modeladas durante varios milenios, consiguiendo paisajes, culturas agrícolas y un espectro de especies vegetales útiles que permiten explicar el marco agrícola y etnobotánico de la España del siglo XV.

La Península Ibérica no había sido solamente puente y punto de contacto de las floras Laurásica y Gondwánica durante tiempos geológicos anteriores a la aparición del hombre. Su particular posición geográfica sirvió durante el Meso y Neolítico además de lugar de paso entre los pueblos del Norte de Africa y Sur de Europa, también como final de camino en los largos procesos de transporte desde Oriente hacia Occidente, a lo largo de las costas e islas del Mediterráneo. Durante el milenio anterior a la era cristiana llegaron hasta los dominios de Celtas, Astures, Vascones e Iberos, los comerciantes, culturas e invasiones Fenicias, Griegas, Cartaginesas y Romanas. Después del siglo I d.C., prosiguió el transporte desde Asia Menor, desde Africa y desde toda la Cuenca Mediterránea hacia la Península Ibérica gracias al Imperio Romano. Más tarde, y a pesar de la caída de este Imperio en el siglo IV, el Reino Visigodo que se establece en la Península Ibérica, mantuvo contactos y recibió cierta influencia de Bizancio (el Imperio Romano en Oriente), especialmente en los siglos VI y VII, gracias a las cuales continuó la transferencia cultural de Oriente a Occidente así como el transporte de especies agrícolas, medicinales y aromáticas.

Pero es a partir del siglo VIII, y más aún del X cuando entramos en el capítulo de la historia de los pueblos y culturas ibéricas de mayor trascendencia para conocer el legado que, siglos después sería transferido hacia América. Nos referimos al periodo hispanoárabe, conocido mejor por los historiadores como período andalusí. Es preciso aclarar que al-Andalus no fue la región meridional que hoy conocemos por Andalucía, sino la totalidad del territorio ibérico bajo dominio musulmán. Aunque el comienzo de este periodo de la historia de los pueblos ibéricos suele identificarse con la invasión de Tarik y la pérdida de la batalla de la Laguna de La Janda por el rey visigodo Rodrigo (año 711) e igualmente se sitúa convencionalmente su final en 1492, con la toma de Granada por los Reyes Católicos, sin embargo y al menos culturalmente, el periodo tiene raíces y finales más difusos y en todo caso su época de esplendor resulta más corta. Por eso desde el punto 
de vista que aquí nos ocupa, reduciremos este intervalo al comprendido entre los siglos X-XIV.

Desde el punto de vista etnobotánico, las consecuencias de este periodo se traducen en muy diferentes aportaciones: especies de interés agrícola introducidas desde Asia y Africa, otras ya conocidas que resultan consolidadas como cultivos importantes, nuevas técnicas agrícolas, manejo y conocimiento de innumerables plantas medicinales, fomento de las Ciencias de la Naturaleza, de la Botánica, de la Farmacología, de la Medicina, etc. Las consecuencias quedaron reflejados en numerosos escritos y tratados, algunos de los cuales han llegado hasta nosotros. Además, estos conocimientos aceptados de forma popular, serán transmitidos desde entonces por vía de la tradición. La llamada Reconquista del Reino Cristiano perseguirá y acabará con la transmisión formal de este patrimonio, quemando y olvidando obras y autores (García Sánchez, 1992). Pero no podrá acabar con la cultura popular que permitirá conservar por generaciones técnicas, costumbres y variedades, muchas de las cuales alcanzarán así las tierras americanas con los primeros colonos, exploradores e agricultores hispanos. El rescate de esta patrimonio etnobotánico andalusí tiene un enorme interés por șí mismo, pues permite recuperar especies marginadas y conocimientos olvidados. Pero además, puede ser igualmente aprovechado por la Etnobotánica y la Botánica Económica Americanas como fuente documental y como forma de estudio de los orígenes y naturaleza de una parte muy significativa de las aportaciones del Viejo al Nuevo Mundo.

Reconocemos la existencia de un cierto desconocimieno sobre esta materia. Varios hechos han contribuido a ello: la pérdida de la mayor parte de los manuscritos originales, su persecución desde el siglo XV a la Ilustración (siglo XVIII), el estar originalmente escritos en árabe y traducidos a otras lenguas sólo en muy contados casos. También hay que mencionar una cierta incomunicación entre los ámbitos científicos de la Filología y el Arabismo con los de la Botánica, Agronomía, Farmacología y Etnobotánica, incomunicación que en nuestro caso nos sentimos muy orgullosos de superar. Finalmente hay que advertir de las dificultades de traducción e identificación de estos textos, especialmente en lo referente a las especies y términos agrícolas empleados. Hemos señalado en alguna ocasión estas dificultades y esbozado el método multidisciplinar para resolverlas (Hernández Bermejo, 1987, 1991). Se han llegado a identificar cultivos asiáticos introducidos en Europa confundiéndolos con especies americanas (Musa paradisiaca con Opuntia ficus indica, o Aloe vera con Agave americana, por ejemplo). Los errores se multiplican si la traducción realizada del árabe al latín, 
o del árabe a una lengua moderna se traduce después a otra lengua moderna. Estas aproximaciones atropelladas han llevado a cierto menosprecio por las posibilidades del análisis científico de estos textos.

\section{Biodiversidad y patrimonio etnbotánico ibérico antes del período andalusí}

La Península Ibérica, había ido acumulando especies de interés económico durante varios milenios antes de la colonización cultural árabe. Procedentes de Centroeuropa, de las Penínsulas Balcánica e Itálica, de Africa, Asia Menor y hasta de Asia Oriental, arribaron hasta este extremo occidental de la Cuenca Mediterránea, numerosas especies vegetales, que unidas a la componente autóctona ibérica, formaban ya en el siglo $\mathrm{X}$, un muy diverso acervo genético. Podemos establecer una cierta cronología de este progresivo enriquecimiento a través de los escritos de naturalistas, médicos, agrónomos y hasta de los literatos griegos y romanos (Estrabón, Plinio, Dioscórides, Virgilio) y mejor todavía gracias a los autores hispanorromanos e hispanovisigodos (Columela, Isidoro de Sevilla).

Por lo tanto y con anterioridad a la influencia árabe, el elenco de especies útiles al hombre en la Península Ibérica era ya notablemente diverso. Los cuadros 1, 2 y 3 , resumen la flora agrícola básica de la Hispania Visigoda antes de la colonización árabe.

CUADRO 1. Componente autóctona

\footnotetext{
Arboles forestales de fruto comestible: Diversas especies constitutivas del bosque mediterráneo fueron aprovechadas por sus frutos, iniciándose un proceso de domesticación, hoy día todavía incompleto. Destacan por ejemplo las especies del género Quercus (encinas, alcornoque, quejigos, robles). Otras, silvestres en ciertas comarcas de la Península pudieron ser objeto de muy antiguos transportes dentro de ella, como es el caso de Corylus avellana (avellano), Castanea sativa (castaño) y Pinus pinea (pino piñonero).

Frutales: Abundarían diversas Rosáceas de frutos comestibles como Crataegus monogyna (espino albar, majuelo), Pyrus spp. (perales silvestres, piruétanos), Sorbus aucuparia, S.aria (serbales, mostajos), Prunus spp. (P.avium, P.mahaleb, P.spinosa). Otros frutos aprovechables serían los de Myrtus communis y Arbutus unedo, así como, de nuevo, los de especies más septentrionales, que pudieron llegar muy pronto hasta la Iberia meridional: Prunus avium (cerezos) y Malus domestica (manzanos)

Cereales: Pudieron ser primitivamente aprovechadas algunas especies silvestres de Hordeum (cebadas) y Avena (avenas).

Leguminosas: Entre ellas se encontrarían diversas especies de los géneros Lathyrus (almortas, guijos, titarros, galganas), Vicia (yeros) y Lupinus (altramuces silvestres)
} 


\section{Botánica económica y etnobotánica en al-Andalus}

Hortícolas: Diversas especies de Apiaceae, Asteraceae, Boraginacea, Chenopodiaceae, Cruciferae y Liliaceae podrían ser aprovechadas en forma silvestre o cultivadas como hortícolas de hoja, fruto o raíz. Entre ellas habría especies de Apium (apios), Daucus (zanahorias), Anchusa y Symphytum (buglosas), Lactuca (lechugas silvestres), Cichorium (achicorias), Chenopodium (cenizos), Rumex (romazas, acederas), diversos cardos como, Scolymus spp. Silybum marianum e incluso Cynara cardunculus. También Asparagus spp.(espárragos), Beta vulgaris (remolachas), Silene spp. (collejas), Diplotaxis spp. y Brassica spp., Raphanus sativus (rábanos), Lepidium spp. (mastuerzos), Nasturtium spp. (berros), Atriplex spp. (armuelles) y Allium spp. (ajetes silvestres).

Otros fuentes de hidratos de carbono: A partir de las semillas de plantas como Polygonum spp. Chenopodium spp. o de las raíces del helecho Pteris aquilinum, podrían obtenerse harinas.

Especias, aromáticas: Una muy rica flora en especias se ofrecía a los primeros pobladores y agricultores ibéricos: Capparis spp. (alcaparras), Laurus nobilis (laurel), Sinapis spp. y Brassica nigra (mostazas), Foeniculum vulgare (hinojo), Ruta graveolens (ruda), diversas Labiadas como Rosmarinus officinalis (romero) y Origanum vulgare (orégano), y otras muchas de géneros como Mentha, Satureja, Thymus (tomillos, mejoranas) y Lavandula spp. (espliegos, alhucemas y cantuesos).

CUADRo 2. Componente alóctona llegada hasta la Península Ibérica desde el Neolítico hasta la Hispania Romana

Frutales y especies forestales de fruto comestible: Olea europaea (olivo) y Vitis vinifera (vid), tal vez por completo alóctonas, procedentes del oriente mediterráneo, se convierten en los dos principales cultivos leñosos de la Península. Otras especies foráneas adquieren una amplia extensión e incluso cierto grado de asilvestramiento como Ceratonia siliqua (algarrobo), Celtis australis (almezos), Ficus carica (higuera) y Juglans regia (nogal). Se consolida e intensifica el aprovechamiento de especies como Pinus pinea (pino piñonero) y Castanea sativa (castaño). Otras especies introducidas son Pyrus communis (peral), diferentes especies orientales de Prunus como P.domestica (ciruelo), P.armeniaca (albaricoquero), P.persica (melocotonero) y P.dulcis (almendro), Phoenix datylifera (palmera datilera), Cydonia oblonga (membrillero), Mespilus germanica (níspero europeo), Ziziphus lotus (azofaifo) y Punica granatum (granado).

Cereales: Los trigos (Triticum spp.), cebadas (Hordeum vulgare) y centenos (Secale cereale) junto a mijos y panizos (Sorghum vulgare, Panicum miliaceum, Setaria spp.) se convierten en la principal fuente de hidratos de carbono.

Leguminosas: Han llegado ya importantes leguminosas del occidente asiático: Cicer arietinum (garbanzo), Vicia faba (haba), Lens culinaris (lenteja) Pisum sativum (guisante) y Vigna sinensis (alubia africana), así como algunas especies más de Lathyrus y Vicia.

Hortícolas: Serían ya cultivadas Brassica napus (nabos), B. oleracea (coles, berzas), Lactuca sativa (lechuga), Apium graveolens (apio), Smyrnium olosatrum (olosatro o apio caballar), Allium cepa (cebolla), A. sativum (ajo), Lagenaria siceraria (calabaza vinatera), entre otras.

Especias, aromáticas: La rica componente autóctona se vió además enriquecida por otras especies orientales y europeas como: Coriandrum sativum (cilantro), Petroselinum crispum (perejil), Carum carvi (alcaravea), Cominum ciminum (comino), Pimpinella anisum (anís o matalauva), Carthamus tinctorius y Anetum graveolens (eneldo). 


\section{La Escuela Agronómica Andalusí. Origen, influencias, principales autores, evolución}

La agricultura, por consiguiente, pudo haber alcanzado un aceptable nivel en la Península Ibérica antes de la colonización romana, con ella desde luego alcanza notable esplendor, pero en época visigótica entra en una fase de estancamiento e incluso regresión.

La llegada de los árabes a partir del s.VIII marca el comienzo de un nuevo y más profundo desarrollo agrícola en la Península Ibérica. Es a partir del siglo $X$ cuando los científicos andalusíes comienzan a hacer aportaciones originales a la ciencia.

Junto a una incipiente tendencia a independizarse de la cultura y ciencia orientales, en al-Andalus van a confluir, a partir de este momento, una serie de elementos y circunstancias que serán el embrión de la llamada "escuela agronómica andalusí". Esta alcanzará su máximo auge en los siglos XI y XII.

La andadura inicial de esta escuela hay que ubicarla en la Córdoba califal, en el círculo de médicos, farmacólogos y botánicos agrupados en torno a los monarcas Abd al-Rahman III (912-961) y su hijo al-Hakam II (961-976). Uno de los acontecimientos que más favorablemente influyeron en el desarrollo de la farmacología y botánica y por consiguiente de la agronomía, fue el envío que el emperador bizantino Constantino VII Porfirogeneta hizo al califa cordobés Abd al-Rahman III, de un ejemplar de la Materia Medica de Dioscórides.

No obstante, fue la redacción, por Arib ben Said del Calendario de Córdoba, el hecho más decisivo en el nacimiento de la escuela agronómica andalusí. El valor de esta obra, dada su antiguedad (siglo $\mathrm{X}$ ) es de capital importancia para el estudio de la botánica y agricultura de la España musulmana. En él se documentan por primera vez, muchas de las especies botánicas introducidas por los árabes en la Península Ibérica, y se da cuenta del cultivo de otras muchas que estaban ya aclimatadas en nuestro suelo y de las que ellos fomentaron su uso o cultivo.

De finales de este siglo $\mathrm{X}$, contamos con otro texto agronómico, Tratado agrícola andalusí anónimo, que posiblemente sea el primero escrito en al-Andalus.

El auge de esta escuela agronómica que conducirá a lo que se ha dado en llamar "revolución agrícola andalusí», se produce en un momento histórico muy concreto: el periodo de descentralización que, a la caída del Califato, llevan a cabo los reinos de taifas (s.XI). A ello hay que añadirle otros factores como: $1^{\circ}$ ) La realización en el Oriente 
musulmán (s.VIII-X) de un vasto programa de traducción de la herencia agronómica grecorromana, bizantina y sobre todo, mesopotámica; $2^{\circ}$ ) el progreso experimentado en los estudios médicos, farmacológicos y botánicos que se inició en Córdoba en los siglos IX y X, y $3^{\circ}$ ) el crecimiento urbano que, al plantear el problema de la seguridad del abastecimiento alimenticio de las ciudades hispano-musulmanas, estimuló, de forma repentina, las investigaciones encaminadas a promover el sector agrícola y a mejorar sus rendimientos. A todo esto hay que añadirle además la riqueza del suelo peninsular y la importante tradición agrícola hispanorromana que encuentran los nuevos pobladores árabes.

En el siglo XI, la «escuela» fundada en Córdoba, cambia de sede, instalándose primero en Toledo y poco más tarde en Sevilla, con una estrecha relación con Granada. Así continúa hasta el siglo XIII. A pesar de la decadencia política y cultural posterior, todavía encontramos en la segunda mitad del siglo XIV el Poema Agrícola de Ibn Luyun.

No se conocen apenas datos biográficos de estos autores. Este hecho, unido al estado misceláneo y resumido en el que se encuentran los diferentes manuscritos agrícolas andalusíes ha dificultado en gran medida su posible estudio. Tenemos únicamente noticias de aquellos que destacaron en otros campos científicos, como es el caso de Ibn Wafid, conocido médico y farmacólogo toledano, maestro de otro de los agrónomos andalusíes, Ibn Bassal.

Este último destaca entre el resto de los andalusíes por su propia personalidad. Sus conocimientos parece que se basan únicamente en experiencias personales y apenas incorpora a su obra información ajena a su propia práctica, como es lo habitual entre los restantes geóponos. Al pasar la taifa toledana a manos cristianas (1085), Ibn Bassal, como el resto de los intelectuales de su ciudad, se trasladó a Sevilla, que a partir de este momento se convertirá en la sede de la "escuela».

En este ambiente aparece ahora Abu l-Jayr, natural de Sevilla, del que apenas sabemos nada, salvo noticias indirectas a través de otros autores que utilizaron su obra. Esta puede considerarse como teórico-práctica. Uno de los autores que mejor representa el enfoque teórico es Ibn Hayyay, del que tampoco conocemos datos biográficos. Al contrario que su coetáneo Ibn Bassal, con quien debió de tener relación (año 1073) constituye un verdadero mosaico de citas de autores antiguos, cotejadas en algunos casos con su propia experiencia. Algunos estudios de su obra (Bolens, 1981), señalan la influencia de la tradición agronómica latina, especialmente de Columela. Esta interpretación se considera sugestiva pero muy discutible. 
Cronológicamente, el ultimo autor del siglo XI, aunque redactó su tratado en los primeros diez años del XII, fue al-Tignari, nacido en una pequeña alquería próxima a Granada. También fue un hábil literato y un excelente poeta $\mathrm{y}$, además médico. Tras viajar por diversos puntos del N. de Africa y Oriente, volvió de nuevo a al-Andalus, alternando su residencia entre Granada y Sevilla. En esta última pasó a formar parte del círculo de agrónomos y botánicos agrupados en torno a Ibn Bassal. De la lectura de su tratado, pese a que sólo nos ha llegado algo menos de la mitad del original, se desprende que es uno de los tratados agronómicos andalusíes más ordenados y sistemáticos, en el que se aunan la teoría con la práctica vivida y experimentada en muy variadas materias, medicina, botánica y lingüística, entre otras.

Habrá que esperar más de un siglo para que Ibn al-Awwam redacte su enciclopedia de economía rural. El tratado de este autor fue, durante bastante tiempo, la única referencia sobre la agronomía hispanomusulmana y, paradójicamente, la personalidad del autor resulta casi totalmente desconocida, aunque por el estudio interno de su obra parece claro que el autor vivió en Sevilla entre los siglos XII y XIII. Su tratado agrícola es un cúmulo de citas de textos andalusíes y orientales y precisamente en ello radica uno de sus mayores méritos y trascendencia pues, aparte de constituir un compendio de la teorías agronómicas anteriores, puede ayudar a reconstruir los textos originales de algunos autores, sobre todo hispanomusulmanes, cuya obra sólo nos ha llegado de modo fragmentario o resumido. En esta obra, una de las pocas que se nos ha conservado completa, se recoge todo el saber agrícola y zootécnico de su época. Establece una tradición asumida, una reflexión que procede de la experimentación, tal como él mismo afirma: «Ninguna sentencia establezco en mi Obra que yo no haya probado por la experiencia repetidas veces».

Entrado el siglo XIV nos encontramos con la última obra conocida de la agricultura andalusí: un poema de tipo didáctico compuesto por el almeriense Ibn Luyun (m. 1349). En ella aparecen conocimientos agrícolas, entresacados básicamente de los tratados de Ibn Bassal y al-Tignari. No obstante, también le concede importancia el hecho de ser una de las pocas obras agrícolas, junto con la de Ibn al-Awwam, conservadas en su totalidad, acontecimiento prácticamente desconocido entre la literatura agronómica andalusí.

Todos estos autores adquirieron sus conocimientos a través de varias vías o grupos de fuentes: la primera y, al mismo tiempo, la de mayor trascendencia, fue la oriental, de tradición greco-bizantina; la segunda fue la latina y, aunque la constancia de la transmisión de sus cono- 


\section{Botánica económica y etnobotánica en al-Andalus}

cimientos no queda tan clara como en el caso de la griega, indudablemente existió; la última vía es la que procede de la perfecta asimilación del saber autóctono, que constituiría un posible sustrato latino mozárabe. A este conjunto de saberes hay que añadir los conocimientos recogidos y transmitidos por la Agricultura Nabatea, la primera gran obra árabe de agricultura, considerada en su época (comienzos del siglo X) como la representante de la tradición mesopotámica.

Cuadro 3. Escuela Agronómica Andalusí. Principales autores y obras agronómicas

\begin{tabular}{|c|c|}
\hline \multicolumn{2}{|l|}{ Siglo $\mathrm{X}$} \\
\hline $\begin{array}{l}\text { al Zaharawi (?) } \\
\text { (Abulcasis) }\end{array}$ & $\begin{array}{l}\text { Médico cordobés. Posible autor de un Tratado de Agricultura } \\
\text { (Carabaza, 1995) }\end{array}$ \\
\hline Arib ben Said & $\begin{array}{l}\text { Historiador, agrónomo, médico y veterinario cordobés. Autor del primer } \\
\text { Calendario Agrícola (traducción Pellat, 1961) }\end{array}$ \\
\hline Anónimo andalusí & $\begin{array}{l}\text { Autor de un Tratado Andalusí de Agricultura (traducción de López } \\
\text { López, 1990) }\end{array}$ \\
\hline \multicolumn{2}{|l|}{ Siglo XI } \\
\hline Ibn Wafid & $\begin{array}{l}\text { Médico y agrónomo toledano autor de Compendio de Agricultura (traduc. } \\
\text { de Millas Vallicrosa,1943) }\end{array}$ \\
\hline Ibn Hayyay & $\begin{array}{l}\text { Sevillano, autor de la obra titulada Lo que basta saber sobre Agricultura } \\
\text { (traduc. Carabaza, 1988; estudio de Bolens, 1981) }\end{array}$ \\
\hline Ibn Bassal & $\begin{array}{l}\text { Agrónomo toledado, autor de un Tratado de Agricultura (traduc. Millas } \\
\text { Vallicrosa y Aziman, 1955) }\end{array}$ \\
\hline Abu 1-Jayr & Sevillano, autor de un Tratado de Agricultura (traduc. Carabaza, 1991) \\
\hline al-Tignari & $\begin{array}{l}\text { Granadino, autor de la obra titulada Esplendor del jardín y recreo } \\
\text { de las mentes (estudio y traduc. García Sánchez, 1987,1988) }\end{array}$ \\
\hline \multicolumn{2}{|l|}{ Siglo XII } \\
\hline $\begin{array}{l}\text { Ibn al-Awwam } \\
\text { (Abu Zacarías) }\end{array}$ & $\begin{array}{l}\text { Agrónomo sevillano, autor de su Tratado de Agricultura (traduc.de } \\
\text { Banqueri, 1802; estudio Hernández Bermejo y García Sánchez, 1988) }\end{array}$ \\
\hline \multicolumn{2}{|l|}{ Siglo XIV } \\
\hline Ibn Luyun & Granadino, autor de su Tratado de Agricultura (traduc.EGuaras, 1975) \\
\hline
\end{tabular}

\section{Valoración del patrimonio etnobotánico andalusi}

\subsection{Contenido de los tratados agrícolas andalusies}

Los tratados andalusíes, sobre todo aquellos que se han conservado más integramente, siguen el mismo esquema que el adoptado por los 
clásicos (griegos y romanos) y orientales. Los primeros capítulos se dedican a tierras, aguas, abonos, después se inician los temas de fitotecnia, seguidos de los de zootecnia y veterinaria. No es raro que incluyan calendarios de tareas agrícolas, acompañados a veces de otros de carácter astronómico y metereológico, mezclados con referencias de tipo mágico, tradiciones locales $\mathrm{y}$ experiencias tomadas de viva voz de los campesinos. Por último, suelen recoger normas prácticas de economía doméstica, control de plagas y enfermedades de los cultivos e incluso, recomendaciones sobre los factores, tanto físicos como morales,a tener en cuenta en la elección de los trabajadores y encargados de las explotaciones agrarias.

Algunos, como es el caso del Libro de Agricultura de Ibn Bassal, son eminentemente prácticos, manuales escritos por un técnico agrícola, que debieron ser de gran utilidad para los agricultores emprendedores de la época. Otros son simples catálogos o elencos de especies como la obra del médico cordobés del siglo X al-Zahrawi. De la misma época y origen es como ya hemos dicho el original e interesantísimo Calendario Agrícola de Arib ben Said, con el que descubrimos no sólo el paisaje sino el ritmo de la agricultura mediterránea de hace mil años. Otras, tienen carácter enciclopédico y a modo de revisión exhaustiva citan autores, comentan experiencias propias y ajenas y sacan conclusiones como el mejor de los rigores cientícos. La obra de Ibn al Awwam es sin duda la más destacable en este estilo.

Llama poderosamente la atención la preocupación de mujhos de estos autores y tratados por aspectos que hoy consideraríamoe característicos de una agricultura moderna diseñada bajo el criterio de la sostenabilidad, casi diríamos de una agricultura ecológica. Destaca por ejemplo, la obsesión por el reciclaje de nutrientes, el uso bien discriminado de estiércoles, los aspectos preventivos respecto a plagas y enfermedades, las técnicas de control basadas en repelentes naturales, el uso de ciertos tratamientos que hoy reconoceríamos como fitohormonales para facilitar la propagación vegetativa y el enraizamiento, etc.

Otro aspecto muy valioso es el paisaje y estructura agrícolas que nos describen, caracterizado por el manejo de una muy elevada diversidad. El número de especies mencionadas en casi todos estos tratados no sólo supera los de autores de épocas y culturas anteriores, lo cual resultaría razonable, sino también el de los compendios y modelos de agricultura coetáneos y posteriores (Alonso de Herrera, 1513) de los Reinos Cristianos circundantes, con una alimentación fundamentada en la trilogía carne-trigo-vino y agricultura más extensiva y de secano. 


\section{Botánica económica y etnobotánica en al-Andalus}

Frente a ella, el manejo del agua en los regadíos, la ocupación de los fondos de los valles y riberas con huertas y el manejo de cultivos arbóreos de secano (almendros, dehesas de encinas y algarrobos, higueras, azofaifos, pistachos y desde luego también y muy destacadamente vid) convertían la agricultura, forma de vida y alimentación hispanoárabes en algo mucho más complejo. Esta diversidad a nivel específico venía acompañada del conocimiento y manejo de muy diferentes variedades. Algunos autores entran con detalle en la descripción de diferencias morfológicas y en el uso de dichas variedades.

Una componente de esta diversidad está constituída por especies hoy olvidadas o marginadas en la agricultura contemporánea, algunas con carácter muy general como es el caso de Silybum marianum, Cichorium intybus, Eruca sativa y Smyrnium olosatrum, otras desaparecidas sólo de la agricultura ibéríca, aunque cultivadas en otras regiones del mundo como Zizyphus lotus, Pistacia vera, Portulaca oleracea, Vigna sinensis, y finalmente, otras casi desaparecidas en nuestra región de referencia son sin embargo transmitidas desde aquí a tierras americanas, como Cichorium intybus, Vigna sinensis, Coriandrum sativum y Lathyrus vulgaris.

Tomemos como ejemplo la obra del toledano Ibn Bassal, que no es ni con mucho el más exhaustivo de los autores. Su obra es una de las menos prolijas por su ya mencionado caracter práctico. Aprovechando una reciente revisión y análisis realizado por nosotros resumimos en el Cuadro 5 las especies citadas por este autor, que podrían representar una flora agrícola básica del Siglo XI. Considerése al analizar el catálogo que no ha llegado hasta nosotros la totalidad de la obra, sino un resumen de la misma, pudiendo tal vez faltar información más signicativa respecto a cereales y otros cultivos de secano.

CUADRO 4. Indice de especies identificadas en el tratado de Agricultura de Ibn Bassal - Siglo XI- modificado a partir de García Sánchez y Hernández Bermejo, 1995

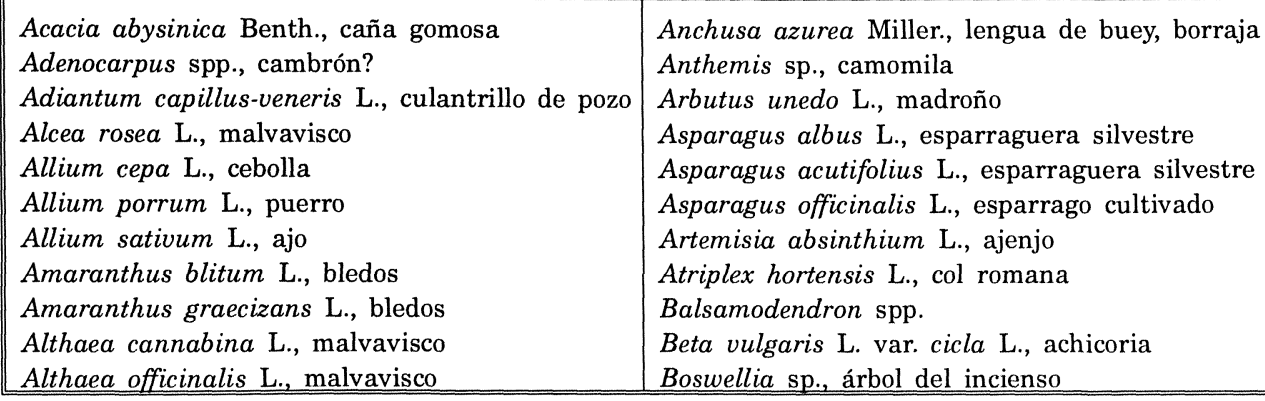

Anchusa azurea Miller., lengua de buey, borraja Anthemis sp., camomila

Arbutus unedo L., madroño

Asparagus albus L., esparraguera silvestre

Asparagus acutifolius L., esparraguera silvestre

Asparagus officinalis L., esparrago cultivado

Artemisia absinthium L., ajenjo

Atriplex hortensis L., col romana

Balsamodendron spp.

Beta vulgaris L. var. cicla L., achicoria

Boswellia sp., árbol del incienso 


\section{J.E. Hernández Bermejo, E. García Sánchez}

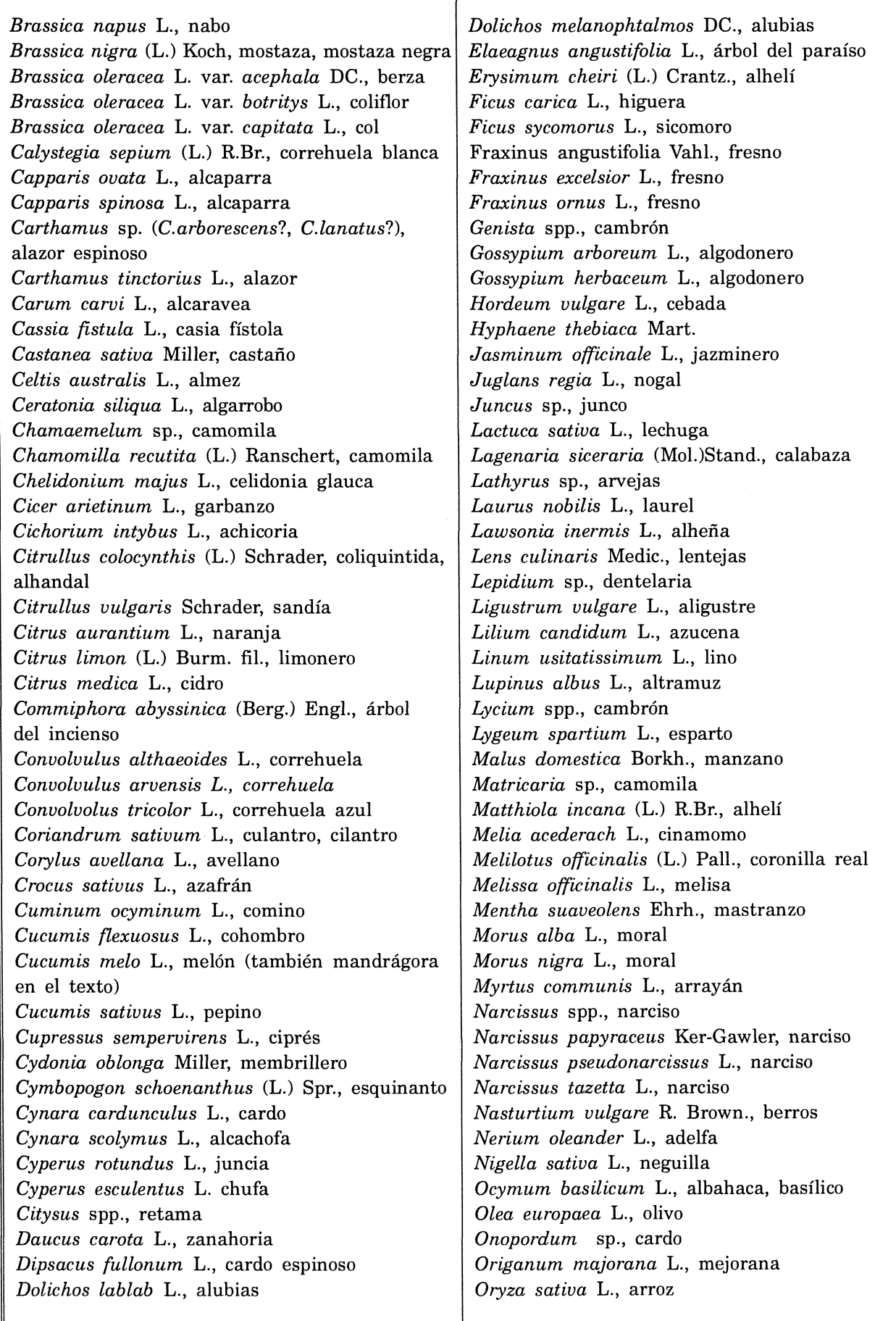




\section{Botánica económica y etnobotánica en al-Andalus}

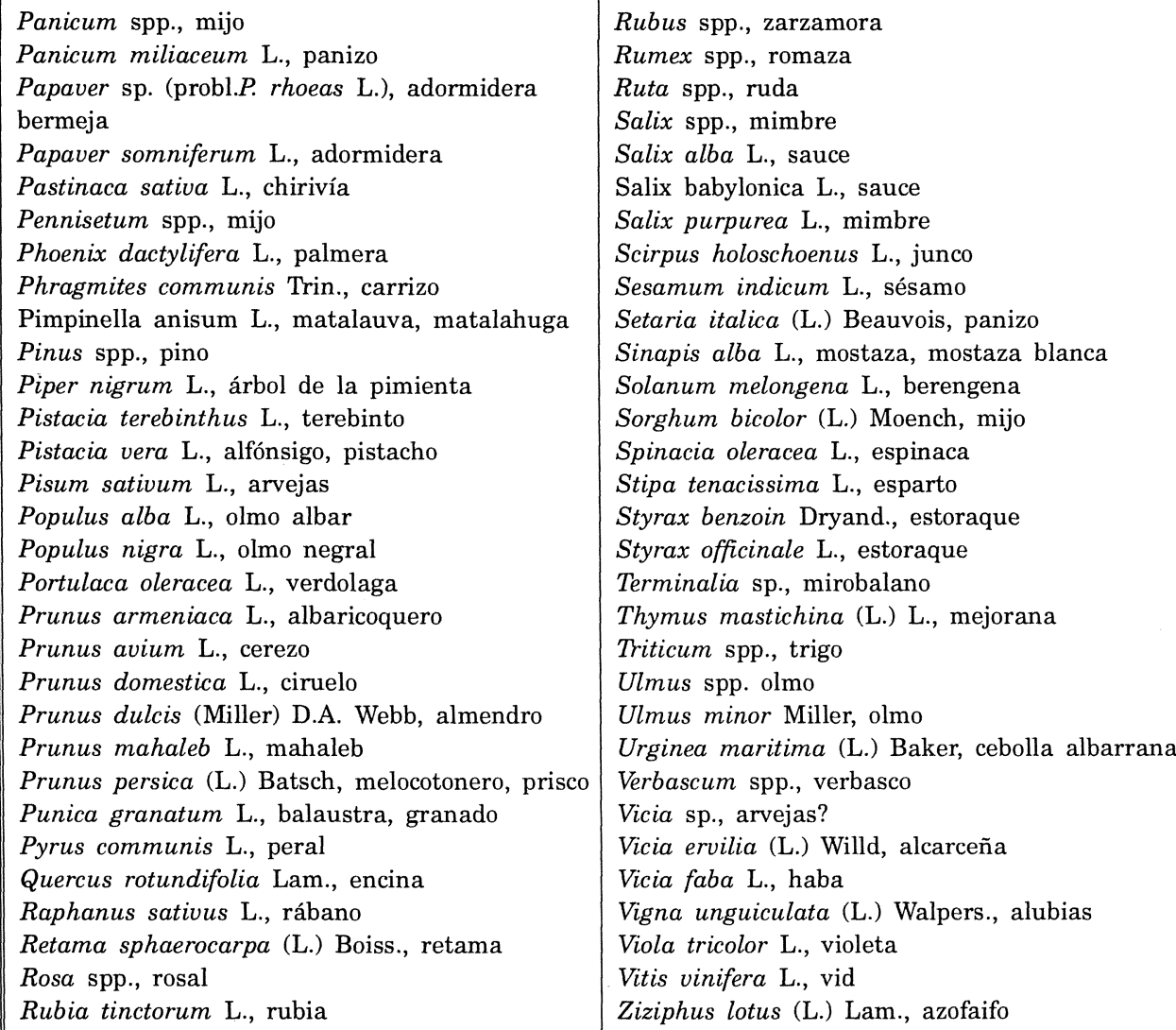

Otro aspecto de gran interés es el estudio de la llegada progresiva de especies orientales. Establecer la cronología de su introducción, el establecimiento efectivo de su cultivo y la evolución de sus formas de aprovechamiento y diversidad varietal, permite reconstruir uno de los episodios más interesantes de la historia de la dispersión de las especies agrícolas. Nos hemos ocupado en alguna ocasión de estos temas comparando la citación progresiva de especies asiáticas y africanas a través de autores hisparromanos, hispanovisigos y de los principales geóponos andalusíes del siglo X-XIV. (Hernández Bermejo, 1991). Entre las especies introducidas en este periodo mencionaremos por ejemplo: 
CuAdro 5. Algunas de las principales especies de interés agrícola introducidas y puestas en cultivo en la Península Ibérica entre los siglos VII - XIV.

\begin{tabular}{||l|c||}
\hline \multicolumn{1}{|c|}{ especie } & $\begin{array}{c}\text { siglo en el que es mencionada por vez } \\
\text { primera, como cultivo ibérico }\end{array}$ \\
\hline Cannabis sativus & $\mathrm{X}$ \\
Carthamus tinctorius & $\mathrm{XI}$ \\
Citrus aurantifolia & $\mathrm{XIV}$ \\
Citrus aurantium & $\mathrm{XI}$ \\
Citrus grandis & $\mathrm{XI}$ \\
Citrus limon & $\mathrm{X}$ \\
Citrus medica & $\mathrm{VII}$ (antes?)* \\
Croccus sativus & $\mathrm{X}$ (VII?) \\
Glycyrrhiza glabra & $\mathrm{VII}$ \\
Gossypium arboreum & $\mathrm{XIII}$ \\
Gossypium herbaceum & $\mathrm{X}$ \\
Indigofera indica & $\mathrm{XI}$ \\
Lawsonia inermis & $\mathrm{X}$ \\
Musa spp. & $\mathrm{X}$ (VII?) \\
Oryza sativa & $\mathrm{X}$ \\
Saccharum officinarum & $\mathrm{X}$ (VII?) \\
Solanum melongena & $\mathrm{X}$ \\
Sorghum spp. & $\mathrm{XI}$ \\
Spinacia oleracea & $\mathrm{XI}$ \\
\hline \hline
\end{tabular}

NOTA $\left(^{*}\right)$ los interrogantes indican posibles fechas anteriores de introducción, debido a la mención de estas especies en las Etimologías de Isidoro de Sevilla.

No conviene, por ahora establecer mas que unas primeras aproximaciones que encuentran las dificultades metodológicas antes mencionadas, junto a las dudas a veces también planteables respecto a si la especie fue simplemente conocida y consumida o realmente cultivada.

Por otra parte, taxones de introducción tradicionalmente atribuída a los árabes en la Península Ibérica, son citadas ya por Isidoro de Sevilla, en el siglo VII. Este es el caso por ejemplo de la caña de azúcar (Saccharum officinarum), cidro (Citrus medica), morales y moreras (Morus spp.), azafrán (Croccus sativus) y de alguna de las especies de algodoneros (Gossypium sp.). Otras parecen conocerse al menos a nivel de consumo, como la pimienta (Piper nigrum), jengibre (Zingiber officinale) y muchas de las especies de canelas y alcanforeros (Cinnamomum spp.).

Entre los autores hispanoárabes de los siglos X-XIV, continúan este tipo de dudas. Hay especies que por su carácter tropical probablemente nunca llegaron a cultivarse en el Occidente Mediterráneo como la pi- 
Botánica económica y etnobotánica en al-Andalus

mienta (Piper nigrum), el añil (Indigofera indica), la canela (Cinnamomum zeylanicum), o el estoraque (Styrax officinale), pero otras hoy desaparecidas de la agricultura ibérica, fueron tal vez cultivos formales en los siglos de referencia, como la alheña (Lawsonia inermis) o el algodonero arbóreo (Gossypium arboreum). Finalmente otras fueron con toda seguridad cultivos frecuentes, pero como hemos dicho anteriormente se encuentran hoy marginados o incluso totalmente olvidados (Pistacia vera, Zizyphus lotus, Vigna sinensis, Linum usitatissimum, Cannabis sativa, Lepidium sativum, Eruca sativa, Portulaca oleracea, Cichorium intybus, Silybum marianum, Myrtus communis, Urginea maritima, etc). Este puede ser por lo tanto otro aspecto de gran interés, que permitiría la recuperación de ciertos cultivos.

\section{2. ¿Una etnobotánica andalusí?}

En el prólogo del Libro de Agricultura de Ibn al-Awwam, el autor, después de manifestar cuales fueron sus fuentes bibliográficas, acaba diciéndonos «Ninguna sentencia establezco en mi Obra que yo no haya probado por la experimentación repetidas veces». Y más adelante, en la Parte Segunda de la misma obra, comienza diciendo algo que repite en otras ocasiones «Dicen [los agricultores] que conviene...». Esto aparece en Ibn al-Awwam, el autor más enciclopedista de la escuela andalusí, pero en otros, como Ibn Bassal, la casi totalidad de sus enseñanzas proceden de su propia experiencia o dicho de otra forma, de los agricultores y hombres de campo de su época.

Sólo la más reduccionista de las definiciones de la Etnobotánica podría poner en duda por lo tanto, el hecho de estar ante una cultura tradicional, transmitida felizmente por escrito por los geóponos andalusíes. Con todo, podríamos aceptar el interes de plantear como cuestión a debate el concepto de "tradicional" en la cultura y época de referencias. Pero lo que entendemos resulta incuestionable es el hallarnos ante una poderosa fuente documental de un patrimonio etnobotánico que prosiguió siendo transmitido por vía oral a través de los siglos, con independencia de su registro escrito por nuestros autores de referencia. Es muy probable que una componente muy significativa de los saberes populares transmitidos de España hacia América en los siglos XVI y XVII y de los todavía conservados en ambas orillas del Atlántico, proceda de aquel antiguo acervo, recogido, procesado y aumentado durante la historia de al-Andalus.

Pondremos algunos ejemplos de su interés etnobotánico: 
a) La planta como parte de la visión cósmica andalusí

¿Existieron especies arbóreas que jugaran para los andalusíes, el papel que otros árboles desempeñan en la visión cósmica de muchas culturas indígenas? ¿Existía algún árbol sagrado o especie en torno a la cual se pueda vertebrar una cosmología para el hispanoárabe?

Resulta desde luego algo arriesgado aventurar respuestas firmes, pero en búsqueda de algunas hipótesis, podemos recordar de entrada, como la palmera datilera (Phoenix dactylifera) es el árbol que mejor define la civilización árabe. El papel que desempeña esta especie y principalmente sus frutos, en la alimentación de las poblaciones nómadas y sedentarias en extensas áreas distribuídas desde Africa Occidental hasta Oriente, queda atestiguado por ejemplo a través de la rica terminología conservada en lengua árabe. Cada elemento morfológico de la palmera posee uno o más vocables en aquella lengua. Igual ocurre con los dátiles, que conservan varios nombres específicos para desginar cada una de las fases de sus procesos de maduración y germinación. Es un árbol frecuentemente citado en el Corán, citado como ejemplo de los dones que la providencia divina ha concedido a la humanidad, pues además de los dátiles, la palmera proporciona otros recursos bastante apreciados en alimentación, artesanía e industria. Los palmerales han constituido siempre para las poblaciones de los desiertos, polos de sedentarización y civilización. La cobertura y sombra de la palmera crean las condiciones favorables para el desarrollo de la vida animal y vegetal.

¿Hasta que punto se tasladó esta obsesión y dependencia a los territorios de al-Andalus? Si bien la palmera no jugó evidentemente el mismo determinante papel que en los desiertos del Norte de Africa y Próximo Oriente, su presencia en la poesía y en los jardines andalusíes fué un hecho constatado desde la Córdoba Califal del siglo $\mathrm{X}$.

Otros árboles debieron competir en este nuevo paisaje de la cultura árabe: los autóctonos alcornoques y encinas (Quercus suber, Q.ilex, Q.rotundifolia) dominaban campos y paisajes, alimentaban hombres y ganados, marcaban el ritmo de las estaciones, calentaban hornos y hogares, permitían la construcción de aperos, útiles y menaje, condicionaban en definitiva ecosistemas y agrosistemas. Junto a ellos el olivo (Olea europaea), la higuera (Ficus carica), el algarrobo (Ceratonia siliqua), el granado (Punica granatum), los almezos (Celtis australis) y las moreras (Morus spp.), eran entre otros árboles, fuente y origen de alimentos, artesanías, costumbres y formas de vida. 
b) El conocimiento de las plantas medicinales

Los agrónomos andalusíes eran personas con una sólida formación en bastantes parcelas del saber, aparte de los estrictamente relacionadas con su dedicación. Hay que tener en cuenta que los estudios de estos «sabios» no se reducían a una disciplina, sino que, como más tarde ocurrió, durante el Renacimiento europeo, en su formación se incluían una serie de materias interrelacionadas, lo que les proporcionaba una amplia visión de los temas que trataban, unos conocimientos enciclopédicos.

Tampoco hay que olvidar que fue la traducción al árabe del Tratado de Materia Médica de Dioscórides, realizada en Córdoba en el s. X a partir del original griego, uno de los hechos que más influyeron en el desarrollo de esta escuela agronómica. A todo ello hay que añadir que buena parte de estos agrónomos eran también médicos (Ibn Waffid, al-Tignari). La obra de Dioscórides se conviertió así en un instrumento imprescindible para los médicos.

En cierta medida, los tratados agrícolas andalusíes están influidos por la teoría médica humoral de origen hipocrático-galénico, aplicada a la clasificación de tierras, aguas, abonos y plantas, teoría que trasciende lo puramente agrícola. Son bastante frecuentes las referencias a propiedades de las especies estudiadas, de las que vamos a presentar algunos ejemplos:

El membrillo es clasificado de antidepresivo, siguiendo una terminología actual, igual que el manzano. Las lentejas "engordan la sangre", en alusión a su alto contenido en hierro. El aceite de las semillas del alazor tiene aplicaciones médicas (no se especifican). Propidades afrodisiacas de los nabos, igual que los puerros y el aceite de manzanilla. La coloquíntida se emplea en la preparación de laxantes. Las castañas tienen propiedades vermífugas, como los garbanzos y el jugo extraído de las hojas del albaricoque; la algarroba es diurética. A los garbanzos también se les reconocen virtudes emenagogas, entre otras. Las hojas y cáscara del limón, se emplean como antídotos frente a ciertos venenos, igual que el anís (García Sánchez, 1981-82).

Pero no sólo citan las propiedades curativas (benéficas), sino que previenen contra las alteraciones orgánicas derivadas de la ingesta prolongada (demasiado frecuente) de algunas de ellas. Así, intuyen las consecuencias del fabismo, al atribuirle a las habas la producción de la alteración del sueño y problemas visuales.

Incluso, describen métodos en los que se introducen a las plantas, generalmente por medio de desgarrados (desgarros), determinadas dro- 
gas con el fin de la planta crezca con las propiedades de la sustancia introducida y poder aprovecharla íntegramente.

Lógicamente, los aspectos dietéticos y terapéuticos de las especies espontáneas y cultivadas señalados por los agrónomos andalusíes hay que encuadrarlos dentro de los parámetros marcados por la medicina medieval en general. Por tanto, en ellos aparecen conceptos hoy totalmente olvidados, pero que tras una lectura minuciosa y crítica, podemos encontrar una vigencia y empleo actuales o, también una posible reutilización de ciertas aplicaciones en desuso actualmente.

c) Conocimiento y manejo de las especies silvestres

Pese a su decidido interés por el cultivo de las especies, no quedan sin embargo olvidadas las silvestres, bien por ser explotadas directamente de sus poblaciones naturales, bien por sus cualidades que las convierten en foco de conocimientos y aplicaciones. Así y entre las primeras, se recolectan los frutos de diferentes especies como Rhamnus spp., Rubus spp., Arbutus unedo, Myrtus communis, Crataegus monogyna, Sorbus spp, etc, o la madera de Salix spp y Populus spp. Entre las segundas, se aprovecha la adelfa (Nerium oleander) para matar liendres, piojos y otros parásitos del cabello; el mirto (Myrtus communis) se recolecta también por su aplicación en cosmética (ennegrece y dá fuerza y vigor al cabello); la cebolla albarrana (Urginea maritima) se utiliza para matar ratones con las hojas de las palmeras (Phoenix dactylifera) se hacen cuerdas; se conocen las virtudes estimulantes de plantas como la oruga (Eruca sativa), el mastuerzo (Lepidium sp.) o el apio caballar (Smyrnium olusatrum), etc. El catálogo es enorme y está recopilar.

\section{Conclusiones: perspectivas de la investigación filológica y etonobotánica en los autores hispanoárabes}

El conocimiento de la agricultura en al-Andalus, el del elenco de especies cultivas o utilizadas en forma de silvestre, de sus técnicas de aprovechamiento, formas de conservación y consumo, etc, es una materia sobre la que nos queda aún mucho por investigar, decir $\mathrm{y}$, lo que es más importante, analizar a la luz de sus posibilidades de aplicación ulterior. No sólo constituye parte de un patrimonio cultural pasado sino además, un conjunto de conocimientos que nos permitirá 


\section{Botánica económica y etnobotánica en al-Andalus}

interpretar mejor la historia y evolución de las relaciones hombre-planta, así como recuperar especies y conocimientos útiles para la humanidad.

Olvidado durante mucho tiempo por parte de arabistas e historiadores de la ciencia, reaparece ahora el interés por el tema, lo que ha permitido se hayan iniciado diferentes proyectos sobre el mismo. La primera fase a seguir - tal como se está ya haciendo- es, forzosamente, de carácter filológico, pues estos tratados, conservados muchas veces en forma de manuscrito y muy pocos veces traducidos hace ya muchas décadas o incluso siglos, requerían de un proceso de revisión o traducción rigurosas, antes de poder iniciar trabajos de otra índole. Esta labor entraña una especial complejidad en la identificación e interpretación de los nombres de las plantas citadas en los textos, pues a los problemas estrictamente filológicos hay que añadir otros, como puedan ser la aplicación de un nombre vulgar a diferentes especies vegetales, o el caso contrario, que una misma especie reciba varios nombres vulgares, todo lo cual conlleva a contradicciones y equívocos entre nombres científicos y vulgares. Estas y otras muchas cuestiones han hecho necesario la formación de un grupo multidisciplinar en el que colaboran arabistas, agrónomos y botánicos, que desde finales de los 80 esta desarrollando una serie de proyectos incluidos en los planes de investigación nacionales y regionales encaminados a un mejor conocimiento de la agronomía andalusí.

En definitiva, debemos reconocer que la agronomía hispanoárabe de los siglos XI-XIII fue, sin lugar a dudas, la de mayor importancia y trascendencia en el mundo musulmán de esta época. Por otra parte, hay que conceder a la geoponimia hispanoárabe, recopiladora del saber agronómico anterior e innovadora en tantos aspectos, el mérito de haber dejado su impronta en los conocimientos y prácticas agrícolas del Occidente cristiano y a través de ella, haber cruzado incluso el Atlántico, llegando a entremezclarse a través de los primeros colonos europeos en el Nuevo Mundo con el saber de los aborígenes y con el resto de culturas importadas desde otras tierras y por otros pueblos.

\section{Referencias}

Alonso de Herrera (1513, ed. 1981). Agricultura General. Ed. facsímil. Ministerio de Agricultura. Madrid.

BANqUeRI, J.A. (translation) (1802). Al-Awwam: Kitab al-filaha. (Libro de Agricultura). Imprenta Real . Madrid.

Bolens, L. (1981) Agronomes andalous du Moyen Age. Droz, Ginebra. 
Carabaza Bravo, J. (1988) Ahmad b. Muhammad b. Hayyay: Lo que basta saber sobre agricultura, 2 vols. Universidad de Granada, Granada.

Carabaza Bravo, J. (1991) Tratado de agricultura de Abu l-Jayr. Instituto de Cooperación con el Mundo Arabe. Madrid.

Carabaza Bravo, J. (1994) Plantas en Al-Andalus en el siglo XI. Monografías Jardín Botánico de Córdoba. Vol. 1.

Crosby, A.W. (1991) El intercambio transoceánico. Consecuencias biológicas y culturales a partir de 1492. Instituto de Investigaciones Históricas. Serie Historia General, 16. Universidad Nacional Autónoma de México. México, D.F.

Dawson, G. (1960) Los alimentos vegetales que América dió al mundo. Serie Técnica y Didáctica $\mathrm{n}^{\circ}$ 8. Facultad de Ciencias Naturales y Museo de la Universidad Nacional de La Plata. La Plata.

Dozy (ed., translation by PELLAT) (1961) Le Calendrier de Cordoue de l'année 961. E.J. Brill. Leiden.

Estrella, E. (1986) El pan de América. Etnohistoria de los alimentos aborígenes en el Ecuador. Consejo Superior de Investigaciones Científicas. Centro de Estudios. Madrid.

García París, J. (1991) Intercambio y difusión de plantas de consumo entre el Nuevo y el Viejo Mundo. Servicio de Extensión Agraria. Ministerio de Agricultura, Pesca y Alimentación. Madrid.

García SÁnchez, E.(1987-88) El tratado agrícola del granadino al-Tignari. Quaderni di Studi Arabi. Vol. V-VI: 278-291.

GARCIA SANCHEZ, E. (1988) Al-Tignari y su lugar de origen. Al-Qantara, IX: 1-11.

Garcta SÁNChez, E. (1992) Agriculture in Muslim Spain, in The Legacy of Muslim Spain, SALMA KHADRA JAYYUSI ed. Handbuch der Orientalistik. I. Abteilung, Leiden-Köln, pp. 987-999.

García SÁnchez, E. y J.E. Hernández Bermejo (1995). Análisis y valoración agronómica y botánica del Kitab al-Qasd wa-I-bayan. El Legado Andalusí. Granada.

Eguaras, J. (1975) Ibn-Luyun: Tratado de Agricultura. Patronato de la Alhambra y Generalife. Granada.

Hernández Bermejo, J.E. (1987). Aproximación al estudio de las especies botánicas originariamente existentes en los Jardines de Madinat al Zahara. Cuadernos Madinat al Zahara. Vol. I: 61-80.

Hernández Bermejo, J.E. y E. García SÁnchez (1988).- Estudio preliminar al Libro de Agricultura de Ibn al-Awwan. In IBN AL-AWWAN. Ministerio de Agricultura. Madrid. 11-46.

Hernández Bermejo, J.E. (1991). Botanical Foundations for the Restoration of Spanish Arabic Gardens: Study of the Plant Species Used and their Introduction during the Andalusi Period. 153-164. in The Authentic Garden, TJON SIE FAT \& DE JONG eds. Leiden.

Hernández Bermejo, J.E. y J. León, eds. (1995). Neglected Crops: 1492 from a different perspective. Food and Agriculture Organizacions of the United Nations. Roma.

Hernández Bermejo, J.E. y A. Lora González (1995) El transporte recíproco entre América y Andalucía de especies agrícolas de interés alimentario. Instituto de Investigaciones Históricas. UNAM, México.

Isidoro de Sevilla (siglo VI, ed. 1982) Etimologías. Texto en latín. Traducción y revisión por J. Oroz Reta y M. Marcos Casquero. Madrid, BAC. 


\section{Botánica económica y etnobotánica en al-Andalus}

López LóPez, A. (1990) Un tratado agrícola andalusí. C.S.I.C. Granada.

Lora GonZÁlez, A. (1994) El papel de España en la introducción de especies vegetales de interés económico procedentes de América. Tesis Doctoral. Universidad de Córdoba.

Millas Vallicrosa (1943) La tradución castellana del tratado de Agricultura de Ibn Wafid. Al Andalus 8:281-332.

Millas Vallicrosa y Aziman, (1955) Ibn Bassal: Libro de Agricultura. Instituto Muley El-Hassan. Tetuán.

Río Moneno, J.A. del (1991) Los inicios de la agricultura europea en el nuevo Mundo (1492-1542). Asaja. Sevilla. 